\title{
Comparison of Clinical Outcomes and Pathological Characteristics of Self-Expandable Stent Bridge to Surgery and Emergency Surgery in Obstructive Colon Cancer
}

\author{
Bingyan Wang ${ }^{1, *}$ \\ Siyi Lu'* \\ Zhiqiang Song ${ }^{2}$ \\ Fei Li' \\ Junren $\mathrm{Ma}^{\prime}$ \\ Yanpeng $\mathrm{Ma}^{\mathrm{I}}$ \\ Xin Zhou' \\ Wei Fu (1D)
}

'Department of General Surgery, Peking University Third Hospital, Beijing,

People's Republic of China; ${ }^{2}$ Department of Gastroenterology, Peking University

Third Hospital, Beijing, People's Republic of China

*These authors contributed equally to this work
This article was published in the following Dove Press journal:

Cancer Management and Research

\begin{abstract}
Aim: Obstructive colon cancer can be treated by self-expanding metal stents (SEMS) prior to definitive surgery. However, the oncological outcome remains controversial, especially regarding whether stent placement or obstruction results in more perineural invasion (PNI) or lymphovascular invasion (LVI). This study aimed to compare clinical outcomes of emergency surgery (ES) and stent as bridge to surgery (SBTS) in patients with obstructive colon cancer. The pathological characteristics were also compared between obstructive and nonobstructive cancer.
\end{abstract}

Methods: This study included 880 patients (including 47 ES and 45 SBTS) admitted to Peking University Third Hospital from January 2010 to December 2018. Short-term and long-term outcomes were compared. The pathological differences between an equal number of obstructive and nonobstructive patients matched using propensity scores were investigated.

Results: SBTS patients had less intraoperative blood loss $(P<0.001)$, shorter ICU stay time $(P=0.007)$, lower incidence of colostomy $(P<0.001)$, and higher laparoscopic achievement $(P<0.001)$ than did ES patients. No pathological difference was found between the two groups. SBTS patients showed better overall survival $(86.7 \%$ vs $68.1 \%, P=0.029)$, but not disease-free survival $(68.9 \%$ vs $59.6 \%, P=0.211)$ than did ES patients. PNI was significantly higher in obstructive cancer than in nonobstructive cancer $(29.3 \%$ vs $16.3 \%, P=0.035)$.

Conclusion: SBTS had a lower incidence of short-term complications and did not affect long-term prognosis compared with that of ES, indicating that SBTS is a safe and effective treatment. Further, PNI may be associated with obstruction, but not with stent insertion.

Keywords: colon obstruction, stenting, bridge to surgery, perineural invasion

\section{Introduction}

Colon cancer is the third most common malignancy. ${ }^{1}$ Approximately $8-29 \%$ of colon cancer patients develop symptoms of intestinal obstruction and require emergent decompression surgery. ${ }^{2-4}$ However, many studies indicate that perioperative mortality and complication rates of emergency surgery (ES) are significantly higher than those of elective surgery, while the proportion of colostomies increases greatly. ${ }^{5}$ In recent years, with the development of endoscopic techniques, colon stenting has provided an alternative treatment for patients with acute colorectal obstruction. This endoluminal decompression method, either as palliative care or as a bridge to surgery, was indicated to be a safe and effective alternative.
Department of General Surgery, Peking University Third Hospital, Beijing 100191, People's Republic of China Email fuwei@bjmu.edu.cn; zhouxinasd@sina.cn 
Numerous studies have explored the safety and effectiveness of this approach. ${ }^{6-10}$ However, the results are controversial. Most studies concluded that colon stents can effectively relieve intestinal obstruction, thus avoiding emergency surgery, potentially reducing the probability of colostomy, and improving patient quality of life. ${ }^{6}$ However, there has been considerable controversy concerning whether stenting as a bridge to surgery (SBTS) affects longterm prognosis. Most studies have concluded that SBTS is equivalent to ES. ${ }^{7,8}$ However, some studies suggest that colon stenting increases the risk of metastasis, ${ }^{9}$ while others draw the opposite conclusion. ${ }^{10}$

Furthermore, lymphovascular invasion (LVI) and perineural invasion (PNI) detrimentally affect the survival of patients with colon cancer. ${ }^{11} \mathrm{~A}$ recent study found that obstruction is associated with PNI and may contribute to increased postoperative recurrence in colon cancer. ${ }^{12}$ Therefore, it is important to further explore whether pathological factors such as LVI and PNI are associated with obstruction or stent placement.

To help guide clinical decisions, our study aimed to compare short-term and long-term outcomes between patients who underwent ES and those who underwent SBTS. We also aimed to explore whether there were pathological differences between patients with obstructive cancer and those with nonobstructive colon cancer, as well as between patients who underwent ES and those who underwent SBTS.

\section{Methods}

\section{Patients}

This was a single-center retrospective study involving 880 colon cancer patients who were admitted to Peking University Third Hospital and received radical operation at the Department of General Surgery from January 2010 to December 2018. Among these patients, 92 had emergency intervention, including 47 who received ES and 45 who were treated with SBTS. All patients had significant abdominal pain associated with cessation of defecation and had the disease state confirmed by enhanced CT, which showed a specific colonic mass with obvious enlargement of the proximal intestinal tract.

Inclusion criteria for emergency intervention were 1) patients who had emergency admission with symptoms of colorectal obstruction and chose either ES or SBTS treatment, 2) patients with pathologically confirmed colon cancer, and 3) patients who underwent radical tumor resection. The exclusion criteria were 1) patients with elective surgery without obvious symptoms or with complete remission of symptoms after emergency admission and who no longer needed emergency intervention; 2) patients with benign masses or extraintestinal lesions; 3) patients who could not tolerate radical surgery, and only underwent palliative resection or stoma creation; 4) patients without elective surgery after stent implantation; and 5) patients who underwent two-stage surgery (emergency diversion followed by radical surgery).

All patients in the SBTS group underwent bowel preparation with polyethylene glycol but not oral antibiotic. Based on the embryonic tissue origin, the cecum, ascending colon, and proximal two-thirds of the transverse colon were defined as right-sided colon, whereas the descending colon, sigmoid colon, and distal third of the transverse colon were defined as left-sided colon.

All patients provided signed informed consent, and this study was conducted with the approval of the ethics committee of the Peking University Third Hospital.

\section{Study Endpoints}

The primary endpoints were overall survival (OS) and disease-free survival (DFS) for all patients. OS was defined as the time from surgery to death from any cause, and DFS as the time from surgery to relapse/death from any cause, whichever came first. The secondary endpoints were shortterm postoperative outcomes, including postoperative mortality rate, stoma rate, and postoperative complication rate within 30 days. Postoperative complications included wound infection, pulmonary infection, inflammatory ileus, heart complication, cerebral vascular accident, renal insufficiency, sepsis, and anastomotic leakage that occurred within 30 days after surgery. Pathological factors including TNM stage, LVI, PNI, and tumor deposit were compared.

To explore the relationship between obstruction and pathological factors, the 92 patients receiving emergency treatment were compared with all 788 patients with nonobstructive colon cancer. To further control other influencing factors and to explore the pathological differences, an equal number of patients exhibiting nonobstructive colon cancer $(\mathrm{n}=92)$ was matched by TNM stage using the propensity score method.

\section{Statistical Analysis}

Statistical analysis was conducted using SPSS version 24.0 (SPSS, Chicago, Illinois, USA). Quantitative variables are presented as mean $\pm \mathrm{SD}$ or median and interquartile range (IQR: Q25-Q75\%); categorical variables are presented as number of observations. Normality was tested using the 
Shapiro-Wilk test. Since the distributions were nonnormal, differences between two independent samples for continuous data were analyzed using the Mann-Whitney $U$-test. For categorical variables, statistical analysis was based on Pearson's chi-squared test. The Kaplan-Meier method was used to estimate the OS and DFS probabilities, and differences were compared using the log-rank test. Univariate and multivariate Cox proportional hazard models were used to test the independent association between clinical procedure-related factors and OS or DFS. Patients with nonobstructive colon cancer were matched 1:1 with patients with obstructive colon cancer using a propensity score with a logistic model. All tests were 2 -sided, and a $P$ value less than 0.05 was regarded as statistically significant.

\section{Results}

\section{Patient Characteristics}

Patient characteristics are summarized in Table 1. A total of 47 patients were included in the ES group and 45 in the SBTS group. There were no statistically significant differences between the two groups in age $(P=0.138)$, sex $(P=0.525)$, body mass index (BMI) $(P=0.619)$, American Society of

Table I Comparison of Patient Characteristics Between ES and SBTS Groups

\begin{tabular}{|c|c|c|c|}
\hline Patients & $\begin{array}{l}\text { ES Group } \\
(n=47)\end{array}$ & $\begin{array}{l}\text { SBTS Group } \\
(n=45)\end{array}$ & $p$ value \\
\hline Age (years) & $68.4( \pm \mid 2.76)$ & $64.3( \pm \mid 3.01)$ & 0.138 \\
\hline $\begin{array}{l}\text { Sex, } \mathrm{n}(\%) \\
\text { Male } \\
\text { Female } \\
\text { BMI }\left(\mathrm{kg} / \mathrm{m}^{2}\right)\end{array}$ & $\begin{array}{l}23(48.9) \\
24(51.1) \\
22.54( \pm 3.69)\end{array}$ & $\begin{array}{l}25(55.6) \\
20(44.4) \\
22.89( \pm 2.96)\end{array}$ & 0.619 \\
\hline $\begin{array}{l}\text { ASA Score, n (\%) } \\
\text { I } \\
\text { II } \\
\text { III } \\
\text { IV }\end{array}$ & $\begin{array}{l}3(6.4) \\
32(68.1) \\
10(21.3) \\
2(4.3)\end{array}$ & $\begin{array}{l}5(11.1) \\
36(80.0) \\
4(8.9) \\
0(0)\end{array}$ & 0.153 \\
\hline $\begin{array}{l}\text { Location of Tumor, n (\%) } \\
\text { Right-sided } \\
\text { Left-sided }\end{array}$ & $\begin{array}{l}22(46.8) \\
25(53.2)\end{array}$ & $\begin{array}{l}12(26.7) \\
33(73.3)\end{array}$ & $<0.001$ \\
\hline $\begin{array}{l}\text { Stage of Tumor, } \mathrm{n}(\%) \\
\text { II } \\
\text { III } \\
\text { IV } \\
\text { Follow-up time (months) } \\
\text { Bridge time (day) }\end{array}$ & $\begin{array}{l}27(57.4) \\
17(36.2) \\
3(6.4) \\
16.53(9.2-47.43) \\
\text { / }\end{array}$ & $\begin{array}{l}17(37.8) \\
23(51.1) \\
5(11.1) \\
31.73(9.01-47.84) \\
22.34(5-132)\end{array}$ & $\begin{array}{l}0.381 \\
1\end{array}$ \\
\hline
\end{tabular}

Abbreviations: $\mathrm{ES}$, emergency surgery; SBTS, stent as bridge to surgery; BMI, body mass index; ASA, American Society of Anesthesiologists.
Anesthesiology status (ASA) score $(P=0.153)$, tumor stage $(P=0.163)$, and follow-up time $(P=0.381)$ (Figure 1). There were statistically significant differences in tumor distribution between the two groups. The number of right-sided colon cancer cases was higher in the ES group than in the SBTS group ( $46.8 \%$ vs $13.3 \%$, respectively; $P<0.001$ ). The mean stent indwelling time in the SBTS group was 22.34 days (range, 5-132).

\section{Comparison of Perioperative Outcomes Between ES and SBTS Groups}

Perioperative outcomes are presented in Table 2. There were no statistically significant differences in the durations of total anesthesia $(P=0.102)$ and operation $(P=0.118)$ between the ES and SBTS groups. Postoperative total parenteral nutrition (TPN) duration ( $5.96 \pm 3.85$ vs $5.91 \pm 4.03$ days, respectively; $P=0.750)$ and perioperative mortality (4.3 vs $0 \%, P=0.162)$ were not statistically different between the ES and SBTS groups. Patients in the ES group had higher intraoperative blood loss than those in the SBTS group $(200 \mathrm{~mL}$ vs $75 \mathrm{~mL}$, IQR $100-550$ vs $50-100$, respectively; $P<0.001$ ), longer intensive care unit stay time ( 1 vs 0 day, $P=0.005$ ), and higher incidence of colostomy ( 55.3 vs $11.1 \%, P<0.001)$. The total complication rate in the ES group was higher than that in the SBTS group (21 vs 10 events; $44.7 \%$ vs $22.2 \%$; $P=0.023$ ), but the subgroup analysis indicated a statistically significant difference only for pulmonary infection (10.6 vs 0 , $P=0.024)$ and sepsis ( 8.5 vs $0, P=0.045$ ). The completion rate of laparoscopic surgery in the ES group was significantly lower than that in the SBTS group $(4.3 \%$ vs $71.1 \%, P<0.001)$.

\section{Comparison of Pathological Characteristics Between ES and SBTS Patients}

A comparison of the pathological characteristics between ES and SBTS patients is shown in Table 3. No statistically significant difference was detected in T stage $(P=0.414)$, M stage ( $P=0.158)$, degree of tumor differentiation $(P=0.589)$, LVI $(P=0.411)$, PNI $(P=0.716)$, tumor deposit $(P=0.545)$ and total retrieved lymph nodes (18 \pm 7.31 vs $17.24 \pm 6.29$, respectively; $P=0.597$ ) between ES and SBTS patients. However, there was a statistical difference in N stage $(P=0.034)$, and the SBTS group had more N1 stage patients than did the ES group.

\section{Comparison of Survival Outcomes Between ES and SBTS Patients}

The median follow-up time was 28.01 months (IQR 9.14-47.68) for all included patients. The median 

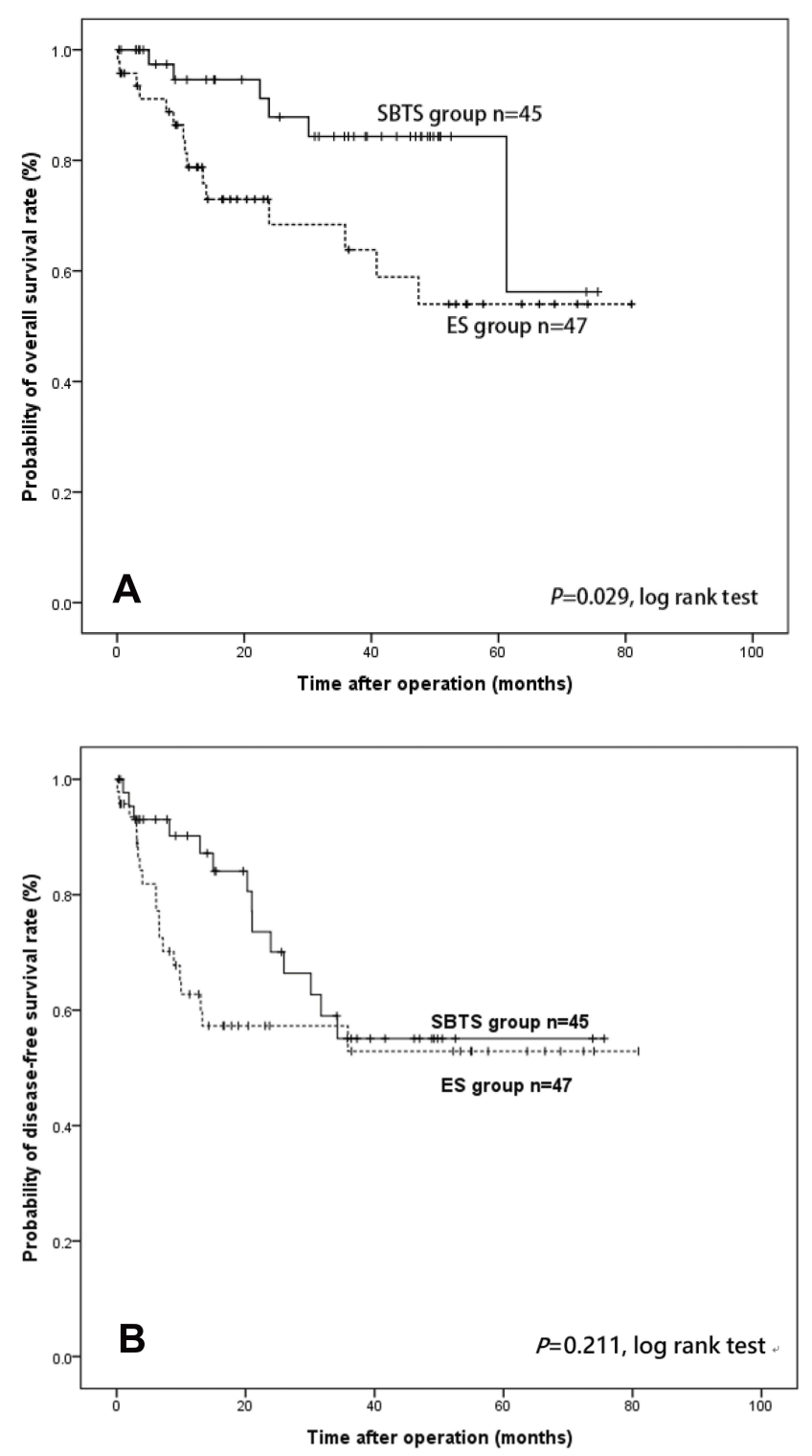

Figure I Kaplan-Meier curves of overall survival (A) and disease-free survival (B) in the emergency surgery and stenting as bridge to surgery groups.

follow-up time for ES and SBTS groups was 16.53 months (IQR 9.2-47.43) and 31.73 months (IQR 9.01-47.84), respectively (Table 1). The SBTS group showed a better accumulative OS than the ES group ( $86.7 \%$ vs $68.1 \%, P=0.029)$. No significant differences in accumulative DFS were found between the ES and SBTS groups (ES $=59.6 \%$ vs $\mathrm{SBTS}=68.9 \%$; $P=0.211$ ). (Figure 1).

\section{Analysis of Prognostic Factors Associated with Survival}

The results of univariate and multivariate analyses of factors associated with OS and DFS are presented in Table 4.
Table 2 Comparison of Perioperative Outcomes Between Patients Undergoing ES and SBTS

\begin{tabular}{|l|l|l|l|}
\hline Patients & $\begin{array}{l}\text { ES Group } \\
(\mathbf{n}=\mathbf{4 7})\end{array}$ & $\begin{array}{l}\text { SBTS Group } \\
(\mathbf{n}=\mathbf{4 5})\end{array}$ & P value \\
\hline Anesthesia time (min) & $288(254-333)$ & $324(265-361)$ & 0.102 \\
Operation time (min) & $227.29( \pm 68.04)$ & $247.27( \pm 70.97)$ & 0.118 \\
Blood loss (mL) & $200(100-550)$ & $50(50-100)$ & $<0.001$ \\
Laparoscopy & $2(4.3 \%)$ & $32(71.1)$ & $<0.001$ \\
Colostomy formation, (\%) & $26(55.3)$ & $5(11.1 \%)$ & $<0.001$ \\
TPN time (day) & $5.96 \pm 3.85$ & $5.91 \pm 4.03$ & 0.750 \\
ICU time (day) & $1(0-3)$ & $0(0-1)$ & 0.005 \\
Total complication & 21 & 10 & 0.023 \\
Wound infection & $6(12.8)$ & $6(13.3)$ & 0.936 \\
Pulmonary complication & $5(10.6)$ & $0(0)$ & 0.024 \\
Inflammatory ileus & $3(6.4)$ & $2(4.4)$ & 0.682 \\
Heart complication & $1(2.1)$ & $0(0)$ & 0.325 \\
Renal insufficiency & $2(4.3)$ & $0(0)$ & 0.162 \\
Sepsis & $4(8.5)$ & $0(0)$ & 0.045 \\
Anastomotic leakage & $0(0)$ & $2(4.4)$ & 0.144 \\
Perioperative mortality & $2(4.3)$ & $0(0)$ & 0.162 \\
\hline
\end{tabular}

Abbreviations: ES, emergency surgery; SBTS, stent as bridge to surgery; TPN, total parenteral nutrition; ICU, intensive care unit.

Multivariate analysis showed that emergency surgery (HR 3.268; 95\% CI 1.253-8.547; $P=0.015$ ), high pT stage (HR $3.425 ; 95 \%$ CI $1.337-8.773 ; P=0.010$ ), positive tumor deposit (HR 4.116; 95\% CI 1.694-10.001; $P=0.002$ ) and positive PNI (HR 2.678; 95\% CI 1.088-6.592; $P=0.032$ ) were independent prognostic factors for OS. BMI (HR 2.997; 95\% CI 1.365-6.583; $P=0.006$ ), tumor deposit (HR 2.855; 95\% CI 1.397-5.834; $P=0.004)$ and PNI (HR 4.154; 95\% CI $1.941-8.891 ; P<0.001)$ were independent prognostic factors for DFS.

\section{Comparison of Pathological Characteristics Between Patients with Obstructive and Those with Nonobstructive Colon Cancer}

To further explore the pathological differences between obstructive and nonobstructive cancer, baseline and pathological characteristics were compared between the 92 emergency-treated obstructive patients and all 788 nonobstructive patients (Table 5). There were significant differences between the two groups in LVI, PNI, and tumor deposit; however, there were significant differences in TNM stage between the two groups as well. Therefore, 92 patients with nonobstructive cancer were selected via the propensity score method that matched the groups for TNM stage, sex, and age, and their pathological characters were compared with the 92 patients with obstructive cancer. No differences were detected in age $(P=0.103)$, sex 
Table 3 Comparison of Pathological Characteristics Between Patients Undergoing ES and SBTS

\begin{tabular}{|c|c|c|c|}
\hline Patients & $\begin{array}{l}\text { ES Group } \\
(n=47)\end{array}$ & $\begin{array}{l}\text { SBTS Group } \\
(n=45)\end{array}$ & $P$ value \\
\hline $\begin{array}{l}\text { Tumor stage } \\
\text { T3 } \\
\text { T4 }\end{array}$ & $\begin{array}{l}28(59.6) \\
19(40.4)\end{array}$ & $\begin{array}{l}23(51.5) \\
22(48.9)\end{array}$ & 0.414 \\
\hline $\begin{array}{l}\text { Nodal stage } \\
\text { No } \\
\text { NI } \\
\text { N2 }\end{array}$ & $\begin{array}{l}29(61.7) \\
7(14.9) \\
I I(23.4)\end{array}$ & $\begin{array}{l}18(40.0) \\
17(37.8) \\
10(22.2)\end{array}$ & 0.034 \\
\hline $\begin{array}{l}\text { Metastasis stage } \\
\text { M0 } \\
\text { MI }\end{array}$ & $\begin{array}{l}44(93.6) \\
3(6.4)\end{array}$ & $\begin{array}{l}38(84.4) \\
7(15.6)\end{array}$ & 0.158 \\
\hline $\begin{array}{l}\text { Differentiation } \\
\text { Well } \\
\text { Moderately } \\
\text { Poorly }\end{array}$ & $\begin{array}{l}0(0) \\
34(72.3 \%) \\
13(27.7 \%)\end{array}$ & $\begin{array}{l}\text { I (2.2) } \\
32(7|.| \%) \\
\text { I2 (26.7\%) }\end{array}$ & 0.589 \\
\hline $\begin{array}{l}\text { LVI, n (\%) } \\
\quad \text { Negative } \\
\text { Positive }\end{array}$ & $\begin{array}{l}35(74.5) \\
12(25.5)\end{array}$ & $\begin{array}{l}30(66.7) \\
15(33.3)\end{array}$ & 0.411 \\
\hline $\begin{array}{l}\text { PNI, n (\%) } \\
\text { Negative } \\
\text { Positive }\end{array}$ & $\begin{array}{l}34(72.3) \\
13(27.7)\end{array}$ & $\begin{array}{l}31 \text { (68.9) } \\
14(31.1)\end{array}$ & 0.716 \\
\hline $\begin{array}{l}\text { Tumor deposit } \\
\text { Negative } \\
\text { Positive } \\
\text { Retrieved lymph nodes }\end{array}$ & $\begin{array}{l}37(78.7) \\
10(21.3) \\
17(14-22)\end{array}$ & $\begin{array}{l}33(73.3) \\
12(26.7) \\
16(13-20)\end{array}$ & 0.597 \\
\hline
\end{tabular}

Abbreviations: ES, emergency surgery; SBTS, stent as bridge to surgery; LVI, lymphovascular invasion; PNI, perineural invasion.
$(P=0.657)$, LVI $(P=0.237)$, tumor deposit $(P=0.730)$, and retrieved lymph nodes $(P=0.744)$ between the two groups. However, there was a significant difference in positive PNI rate between obstructive and nonobstructive cancer (27 vs $15 ; P=0.035)$.

\section{Discussion}

This study compared the perioperative and oncological outcomes between ES and SBTS methods for the treatment of obstructive colon cancer; it also explored the pathological characteristics of patients with obstructive and nonobstructive cancer.

Self-expanding metal stents (SEMSs) have been increasingly used in clinical practice for nearly 20 years. ${ }^{13}$ With continuous improvement in endoscopic technology, SBTS has been widely used in the clinical treatment of colon cancer obstruction.

Most studies conclude that SBTS has non-inferior or better short-term outcomes than does ES and can effectively reduce the probability of colostomy and achieve more primary anastomosis. ${ }^{14,15}$ In the current study, the amount of intraoperative blood loss in the SBTS group was significantly lower than that in the ES group. Further, the ICU stay time and the incidence of perioperative complications were lower than those in the ES group, suggesting that the SBTS method is a safe and efficient treatment option. The colostomy formation rate was significantly higher in the ES group than in the SBTS group, even when the stoma reversal cases were considered. But

Table 4 Univariate and Multivariate Analysis of Factors Associated with Survival

\begin{tabular}{|c|c|c|c|c|c|c|}
\hline & \multicolumn{3}{|l|}{ Overall Survival } & \multicolumn{3}{|l|}{ Disease-Free Survival } \\
\hline & \multirow{2}{*}{$\begin{array}{l}\text { Univariate Analyses } \\
P\end{array}$} & \multicolumn{2}{|c|}{ Multivariate Analyses } & \multirow{2}{*}{$\begin{array}{l}\text { Univariate Analyses } \\
P\end{array}$} & \multicolumn{2}{|c|}{ Multivariate Analyses } \\
\hline & & HR $(95 \% \mathrm{Cl})$ & $P$ & & HR (95\% Cl) & $\mathbf{P}$ \\
\hline Age $(\leq 60$ vs $>60 y)$ & 0.361 & & & 0.145 & & 0.288 \\
\hline Sex (male vs female) & 0.896 & 0.798 & & 0.386 & & 0.299 \\
\hline BMl, $\mathrm{kg} / \mathrm{m} 2(\leq 25$ vs $>25)$ & 0.160 & 0.117 & & 0.024 & $2.997(1.365-6.583)$ & 0.006 \\
\hline ASA score ( $\leq$ III vs >III) & 0.028 & & 0.094 & 0.134 & & 0.088 \\
\hline Surgical approach (SBTS vs ES) & 0.036 & $3.268(1.253-8.547)$ & 0.015 & 0.211 & & \\
\hline Location of tumor (right vs left) & 0.614 & & & 0.924 & & \\
\hline pT (T3 vs T4) & 0.041 & $3.425(1.337-8.773)$ & 0.010 & 0.964 & & \\
\hline $\mathrm{pN}(\mathrm{N}-\mathrm{vs} \mathrm{N}+)$ & 0.480 & & & 0.292 & & \\
\hline Stage of tumor ( $\leq \|$ vs $>\| l)$ & 0.217 & & & 0.165 & & \\
\hline Tumor deposit (- vs +) & 0.007 & $4.116(1.694-10.001)$ & 0.002 & $<0.001$ & $2.855(1.397-5.834)$ & 0.004 \\
\hline PNI (- vs +) & 0.031 & $2.678(1.088-6.592)$ & 0.032 & $<0.001$ & $4.154(1.94 \mid-8.891)$ & $<0.001$ \\
\hline LVI & 0.050 & & 0.208 & 0.256 & & \\
\hline
\end{tabular}

Abbreviations: HR, hazard ratio; BMI, body mass index; ASA, American Society of Anesthesiologists; ES, emergency surgery; SBTS, stent as bridge to surgery; PNI, perineural invasion; LVI, lymphovascular invasion. 
Table 5 Comparison of Baseline and Pathological Characteristics Between Patients with Obstructive and NonoObstructive Colon Cancer

\begin{tabular}{|c|c|c|c|c|c|}
\hline Patients & Obstructive $(n=92)$ & $\begin{array}{l}\text { Nonobstructive (Total) } \\
(\mathrm{n}=\mathbf{7 8 8})\end{array}$ & $\mathbf{P}$ value & $\begin{array}{l}\text { Nonobstructive (Propensity } \\
\text { Score Matched) }(n=92)\end{array}$ & $P$ value \\
\hline Age & $66.45 \pm 12.90$ & $65.43 \pm 12.25$ & 0.464 & $66.20 \pm 13.22$ & 0.130 \\
\hline $\begin{array}{l}\text { Sex, n (\%) } \\
\text { Male } \\
\text { Female }\end{array}$ & $\begin{array}{l}48(52.2) \\
44(47.8)\end{array}$ & $\begin{array}{l}448(56.9) \\
340(43.1)\end{array}$ & 0.392 & $\begin{array}{l}5 I(55.4) \\
4 I(44.6)\end{array}$ & 0.657 \\
\hline $\begin{array}{l}\text { Tumor stage, } \mathrm{n}(\%) \\
\text { TI } \\
\text { T2 } \\
\text { T3 } \\
\text { T4 }\end{array}$ & $\begin{array}{l}0 \\
0 \\
51(55.4) \\
4 I(44.6)\end{array}$ & $\begin{array}{l}42(5.3) \\
138(17.5) \\
488(61.9) \\
120(15.2)\end{array}$ & $<0.001$ & $\begin{array}{l}51(55.4) \\
41(44.6)\end{array}$ & 1.00 \\
\hline $\begin{array}{l}\text { Nodal n (\%) } \\
\begin{array}{l}\mathrm{N}- \\
\mathrm{N}+\end{array}\end{array}$ & $\begin{array}{l}47(5 I .1) \\
45(48.9)\end{array}$ & $\begin{array}{l}508(64.5) \\
280(33.5)\end{array}$ & 0.012 & $\begin{array}{l}60(65.2) \\
32(34.8)\end{array}$ & 0.073 \\
\hline $\begin{array}{l}\text { Metastasis stage, } n(\%) \\
\text { M0 } \\
\text { MI }\end{array}$ & $\begin{array}{l}82(89.1) \\
10(10.9)\end{array}$ & $\begin{array}{l}750(95.2) \\
37(4.7)\end{array}$ & 0.043 & $\begin{array}{l}83(90.2) \\
9(9.8)\end{array}$ & 0.809 \\
\hline $\begin{array}{l}\text { LVI, n (\%) } \\
\text { Negative } \\
\text { Positive }\end{array}$ & $\begin{array}{l}65(70.7) \\
27(29.3)\end{array}$ & $\begin{array}{l}645(81.9) \\
143(18.1)\end{array}$ & 0.01 & $\begin{array}{l}72(78.3) \\
20(21.7)\end{array}$ & 0.237 \\
\hline $\begin{array}{l}\text { PNI, n (\%) } \\
\text { Negative } \\
\text { Positive }\end{array}$ & $\begin{array}{l}65(70.7) \\
27(29.3)\end{array}$ & $\begin{array}{l}687(87.2) \\
101(12.8)\end{array}$ & $<0.001$ & $\begin{array}{l}77(83.7) \\
15(16.3)\end{array}$ & 0.035 \\
\hline $\begin{array}{l}\text { Tumor deposit } \\
\text { Negative } \\
\text { Positive }\end{array}$ & $\begin{array}{l}67(72.8) \\
25(27.2)\end{array}$ & $\begin{array}{l}687(87.2) \\
97(12.3)\end{array}$ & $<0.001$ & $\begin{array}{l}71(77.2) \\
21(22.8)\end{array}$ & 0.730 \\
\hline $\begin{array}{l}\text { Location of tumor, n (\%) } \\
\text { Right-sided } \\
\text { Left-sided } \\
\text { Retrieved lymph nodes }\end{array}$ & $\begin{array}{l}34(37.0) \\
58(63.0) \\
16(13-2 \mid)\end{array}$ & $\begin{array}{l}410(52.0) \\
378(480) \\
16(13-20)\end{array}$ & $\begin{array}{l}0.006 \\
0.846\end{array}$ & $\begin{array}{l}56(60.9) \\
36(39.1) \\
16(13-21)\end{array}$ & $\begin{array}{l}0.001 \\
0.744\end{array}$ \\
\hline
\end{tabular}

Abbreviations: LVI, lymphovascular invasion; PNI, perineural invasion.

it should be noted that most studies only reported the preoperative stoma rate and did not provide the stoma reversal rate. Several randomized controlled studies have not found a significant difference in the rate of permanent stoma formation between the two treatment regimens. ${ }^{16,17}$ In the current study, the higher permanent stoma rate in the ES group compared with that in the SBTS group may be related to the surgeon's cautious approach to emergency surgery. Of note, $11.1 \%$ of patients in the SBTS group underwent colostomy. This is primarily because the relief of intestinal obstruction is not always parallel to the improvement of colon physiological status; therefore, some patients still had significant colon swelling.
Considering that unsatisfactory anastomosis might lead to serious anastomotic leakage, some surgeons still chose to perform colostomy.

There has been significant controversy regarding the long-term prognosis of SBTS compared with that of emergency surgery. A large proportion of studies concluded that SBTS showed at least non-inferior long-term oncological outcomes. ${ }^{7,8}$ Currently, the NCCN guidelines are also in agreement that the prognoses of these two treatments are approximately the same. ${ }^{18}$ However, a previous study indicated that stenting can induce an increase in $C K 20$ mRNA levels in the peripheral blood, suggesting that stenting may increase tumor spread. ${ }^{19}$ Worse overall 
survival and disease-free survival in SBTS patients than in emergency surgery patients were reported previously. ${ }^{20}$ Pooled analysis also indicated a greater chance of recurrence, especially systemic recurrence, in SBTS patients. ${ }^{9}$ On the contrary, several studies concluded that SBTS showed satisfying oncological results. ${ }^{10,21}$ Moreover, a recent retrospective study indicated that SBTS patients showed a better recurrence-free survival rate than did ES patients. ${ }^{10}$ The present data indicate that SBTS patients had a better overall survival rate, but not disease-free survival rate, than did ES patients, suggesting that SBTS may be a promising alternative treatment option. The univariate and multivariate analysis also showed that compared with SBTS, ES is an independent prognostic factor for worse OS. However, it should be noted that neither Kaplan-Meier nor multivariate analysis showed positive results for DFS rate and that even patients receiving SBTS showed a slightly higher AJCC-N stage. This may be due to the small sample size or selective bias.

However, it should be noted that most of the studies were retrospective in nature and included a limited number of patients. In most cases, the physician recommends SBTS based on the patient's condition. If the patient has significant colon obstruction, the doctors may be more inclined to carry out immediate emergency surgical intervention, which may lead to a selection bias between the two groups. Currently, randomized controlled trial (RCT) studies on this topic are limited. The meta-analysis by Foo et $\mathrm{al}^{9}$ included seven RCT studies and concluded that SBTS is associated with a lower rate of overall morbidities but a greater rate of recurrence, especially systemic recurrence, than is ES. Therefore, whether SBTS is a better option than ES remains controversial.

Recently, a retrospective study reported that obstruction is associated with PNI and, consequently, contributes to increased postoperative recurrence in colon cancer patients. $^{12}$ Meanwhile, a recent study showed that PNI and LVI showed negative impacts on survival even in early-stage colon cancer. ${ }^{11}$ Therefore, it is necessary to explore any pathological differences between patients with obstructive and nonobstructive cancer as well as between patients undergoing ES and SBTS. In the present study, Cox regression analysis showed that PNI and tumor deposit were important factors for survival. However, a direct comparison between obstructive and all nonobstructive cancer was inconclusive because of several influencing factors. Therefore, the propensity score method was adopted, and 92 nonobstructive patients were compared with all obstruction patients. PNI was higher in patients with obstruction cancer compared to those with nonobstruction cancer, which is consistent with previous studies. ${ }^{12}$ Other factors like tumor deposit and LVI showed no intergroup differences. This may indicate that PNI was aggravated by mechanical obstruction and not by stent insertion. However, a previous study reported that more PNI was found in stent insertion patients than in emergency operation patients. ${ }^{22}$ Nonetheless, no effects of PNI on oncologic outcomes according to SEMS insertion were detected. In the current study, PNI was found to be an important prognostic factor. The sample size of our study was small; moreover, since both groups had colonic obstruction, the effect of stent placement may have been obscured. In addition, the duration of stent placement may also affect the incidence of PNI and hence, a larger sample study is needed. These results also suggest that more attention should be focused on PNI in postoperative pathology because of its high predictive value for prognosis.

This study had several limitations. This was a singleinstitution retrospective study with a limited number of patients and risk of selection bias. Due to the small sample size, some recently treated patients were also included in this study. Furthermore, the follow-up time was shorter in the ES group than in the SBTS group, and the total followup time may not be sufficiently long, which may affect the accuracy of survival analysis. Additionally, treatment options for patients with colon obstruction depend largely on individual decision-making, which is prone to physician bias. Moreover, for critically ill patients, clinicians are more inclined to adopt emergency surgery rather than SBTS. Lastly, some patients were lost to follow-up, which may have affected the research data.

In conclusion, SBTS had a lower incidence of short-term complications and did not affect long-term prognosis compared with that of ES, indicating that SBTS is safe and effective. Further, PNI may be associated with obstruction, but not with stent insertion. More clinical data are needed to further validate the safety of SBTS, and the mechanism of increased PNI due to obstruction needs further exploration.

\section{Disclosure}

The authors report no conflicts of interest in this work.

\section{References}

1. Siegel RL, Miller KD, Jemal A. Cancer statistics, 2019. CA Cancer J Clin. 2019;69(1):7-34. doi:10.3322/caac.v69.1 
2. Sanoff HK. Best evidence supports annual surveillance for resected colorectal cancer. JAMA. 2018;319(20):2083-2085. doi:10.1001/ jama.2018.5817

3. Carraro PG, Segala M, Cesana BM, et al. Obstructing colonic cancer: failure and survival patterns over a ten-year follow-up after one-stage curative surgery. Dis Colon Rectum. 2001;44(2):243-250. doi:10. 1007/BF02234300

4. Jullumstro E, Wibe A, Lydersen S, et al. Colon cancer incidence, presentation, treatment and outcomes over 25 years. Colorectal Dis. 2011;13(5):512-518. doi:10.1111/codi.2011.13.issue-5

5. Manceau G, Mege D, Bridoux V, et al. Emergency surgery for obstructive colon cancer in elderly patients: results of a multicentric Cohort of the French National Surgical Association. Dis Colon Rectum. 2019;62(8):941-951. doi:10.1097/DCR.0000000000001421

6. Arezzo A, Passera R, Lo Secco G, et al. Stent as bridge to surgery for left-sided malignant colonic obstruction reduces adverse events and stoma rate compared with emergency surgery: results of a systematic review and meta-analysis of randomized controlled trials. Gastrointest Endosc. 2017;86(3):416-426. doi:10.1016/j.gie.2017.03.1542

7. Mege D, Sabbagh C, Manceau G, et al. What is the best option between primary diverting stoma or endoscopic stent as a bridge to surgery with a curative intent for obstructed left colon cancer? Results from a propensity score analysis of the French Surgical Association multicenter Cohort of 518 patients. Ann Surg Oncol. 2019;26(3):756-764. doi:10.1245/s10434-018-07139-0

8. Rodrigues-Pinto E, Morais R, Coelho C, et al. Bridge-to-surgery versus emergency surgery in the management of left-sided acute malignant colorectal obstruction - Efficacy, safety and long-term outcomes. Dig Liver Dis. 2019;51(3):364-372. doi:10.1016/j.dld.2018.11.006

9. Foo CC, Poon SH, Chiu RH, et al. Is bridge to surgery stenting a safe alternative to emergency surgery in malignant colonic obstruction: a meta-analysis of randomized control trials. Surg Endosc. 2019;33 (1):293-302. doi:10.1007/s00464-018-6487-3

10. Lara-Romero C, Vilches Á, Caunedo-Álvarez Á, et al. Better recurrence-free survival after stent bridge to surgery compared to emergency surgery for obstructive left-sided colonic cancer in patients with stage III status of the American Joint Committee on Cancer (AJCC): a bicentric retrospective study. Int J Colorectal Dis. 2019;34(7):1241-1250. doi:10.1007/s00384-019-03318-x

11. Skancke M, Arnott SM, Amdur RL, et al. Lymphovascular invasion and perineural invasion negatively impact overall survival for stage II adenocarcinoma of the colon. Dis Colon Rectum. 2019;62 (2):181-188. doi:10.1097/DCR.0000000000001258
12. Nozawa H, Morikawa $\mathrm{T}$, Kawai $\mathrm{K}$, et al. Obstruction is associated with perineural invasion in T3/T4 colon cancer. Colorectal Dis. 2019;21:917-924. doi:10.1111/codi.v21.8

13. Itabashi M, Hamano K, Kameoka S, et al. Self-expanding stainless steel stent application in rectosigmoid stricture. Dis Colon Rectum. 1993;36(5):508-511. doi:10.1007/BF02050019

14. Kobborg M, Broholm M, Frostberg E, et al. Short-term results of self-expanding metal stents for acute malignant large bowel obstruction. Colorectal Dis. 2017;19(10):O365-O371. doi:10.1111/codi.13880

15. Allievi N, Ceresoli M, Fugazzola P, et al. Endoscopic Stenting as bridge to surgery versus emergency resection for left-sided malignant colorectal obstruction: an updated meta-analysis. Int J Surg Oncol. 2017;2017:2863272.

16. Pirlet IA, Slim K, Kwiatkowski F, et al. Emergency preoperative stenting versus surgery for acute left-sided malignant colonic obstruction: a multicenter randomized controlled trial. Surg Endosc. 2011;25 (6):1814-1821. doi:10.1007/s00464-010-1471-6

17. van Hooft JE, Bemelman WA, Oldenburg B, et al. Colonic stenting versus emergency surgery for acute left-sided malignant colonic obstruction: a multicentre randomised trial. Lancet Oncol. 2011;12 (4):344-352. doi:10.1016/S1470-2045(11)70035-3

18. Matsuda A, Miyashita M, Matsumoto S, et al. Comparison of longterm outcomes of colonic stent as "bridge to surgery" and emergency surgery for malignant large-bowel obstruction: a meta-analysis. Ann Surg Oncol. 2015;22(2):497-504. doi:10.1245/s10434-014-3997-7

19. Maruthachalam K, Lash GE, Shenton BK, et al. Tumour cell dissemination following endoscopic stent insertion. Br J Surg. 2007;94 (9):1151-1154. doi:10.1002/(ISSN)1365-2168

20. Sabbagh C, Browet F, Diouf M, et al. Is stenting as "a bridge to surgery" an oncologically safe strategy for the management of acute, left-sided, malignant, colonic obstruction? A comparative study with a propensity score analysis. Ann Surg. 2013;258(1):107-115. doi:10.1097/SLA.0b013e31827e30ce

21. Kye B-H, Lee YS, Cho H-M, et al. Comparison of long-term outcomes between emergency surgery and bridge to surgery for malignant obstruction in right-sided colon cancer: a multicenter retrospective study. Ann Surg Oncol. 2016;23(6):1867-1874. doi:10.1245/s10434-015-5053-7

22. Kim HJ, Choi G-S, Park JS, et al. Higher rate of perineural invasion in stent-laparoscopic approach in comparison to emergent open resection for obstructing left-sided colon cancer. Int $J$ Colorectal Dis. 2013;28(3):407-414. doi:10.1007/s00384-012-1556-x

\section{Publish your work in this journal}

Cancer Management and Research is an international, peer-reviewed open access journal focusing on cancer research and the optimal use of preventative and integrated treatment interventions to achieve improved outcomes, enhanced survival and quality of life for the cancer patient.
The manuscript management system is completely online and includes a very quick and fair peer-review system, which is all easy to use. Visit http://www.dovepress.com/testimonials.php to read real quotes from published authors. 